\title{
JUAN SANTOS ATAHUALPA Un Movimiento Milenarista en la Selva
}

\section{B. Sara Mateos Fernández-Maquieira}

En junio de 1742, en pleno corazón de la selva central peruana, estalló la más larga rebelión registrada en el período colonial. Encabezada por Juan Santos Atahualpa, un joven mestizo de origen serrano, el movimiento deshizo en pocos meses toda la labor evangelizadora que los franciscanos habían comenzado en la zona en el siglo XVII y consolidado en el XVIII. Esta rebelión con rasgos eminentemente milenaristas, no logró su meta: la de expulsar a los peninsulares del virreynato y coronar a Juan Santos Atahualpa como el nuevo inca del Perú. Este artículo pretende analizar la rebelión desde un punto de vista ideológico, para lo cual se ha creído conveniente explicar la situación de la selva central en esa época.

In June of 1742 , in the heart of the central rainforest of Peru, a rebellion broke out that was the longest ever recorded in the colonial period. Led by Juan Santos Atahualpa, the movement undid in a few months the missionary work that the Franciscans had begun in the region in the VXII century and consolidated in the XVIII century. This rebelion, with evident millenaristic characteristics, did not achieve its goal: to expel the europeans and crown Juan Santos Atahualpa as the new Inca of Peru. This article analyzes the rebellion from an ideological viewpoint, and with this in mind, studies the context of the central rainforest of that period. 


\section{INTRODUCCION}

Este artículo es el resultado de una ponencia que presenté en la Universidad de Lima en noviembre del año pasado. En un ciclo de conferencias sobre movimientos milenaristas, se me pidió analizar la rebelión de Juan Santos Atahualpa para ver si podía ser clasificada como tal.

Para ello creí conveniente comenzar con un marco teórico que definiese de manera global un término como el de milenarismo. Según un experto como M. Curátola, se llama movimiento milenarista a uno que sostiene "...la expectativa de un próximo advenimiento de una nueva era paradisíaca implícita en la ideología del movimiento." (1). Se trata, por lo tanto, de movimiento de renovación. El término, como apunta N. Cohn, aludía originalmente únicamente a la creencia dealgunos cristianos primitivos basada en el libro de la rẹvelación o Apocalipsis, de que Cristo en su segunda venida establecería un reino mesiánico durante 1000 años en esta tierra antes de la llegada del juicio final: "Los ciudadanos de este reino serían los mártires cristianos quienes resucitarían para este fin mil años antes de la resurrección de los demás muertos." (2)

Pero esta profecía no se mantuvo mucho tiempo en su concepto original y ha sido reinterpretada de mil maneras a través de la historia. Así, la salvación, tema principal de este tipo de movimientos, ha sido concebida de muchas formas. 'Surgieron entonces movimientos que han sido catalogadós como milenaristas con características que se alejaban mucho del concepto original de salvación cristiana. Aún así, autores como N. Cohn, M. Curátola y R. Rubio, han podido rescatar lo que consideran características esenciales de este tipo de movimiento.

Según estos autores, todo movimiento milenarista se produce en una situación de aguda crisis social que amenaza ".. la existencia y continuidad de un determinado grupo humano como entidad histórica y cultural" (3). Es por ello que he creído conveniente comenzar analizando cuál era el contexto social y económico de la selva central inmediatamente antes de estallar en ella la rebelión de Juan Santos Atahualpa. Fue una evidente coyuntura de crisis lo que hizo posible el estallido de este movimiento. En este punto se analizará la situación de los habitantes de las misiones selváticas que obedecieron al llamado de J.S.A., una población en proceso de incorporarse a la sociedad colonial pero que aún podía considerarse marginal. Esta es, según Cohn, otra de las premisas de todo movimiento milenarista: hallar principalmente sus 
fuerzas en gente que por uno u otro motivo no encuentra su lugar en la sociedad. Gente "... cuyos grupos de parentesco se habían desintegrado y que esperan la llegadá de alguien que los agrupe nuevamente devolviéndoles la coherencia perdida." (4).

Estas dos premisas, crisis y su consecuente desintegración social, hacen necesario analizar la rebelión también desde un punto de vista político y. rescatar los aspectos reivindicatorios del movimiento en tanto indicadores de los elementos de descontento.

Finalmente, para que surga un movimiento milenarista, es necesaria la aparición 'de un sistema mítico-ideológico que se ajuste y al mismo tiempo justifique el modo de salvación sugerido. En lo que concieme a J.S.A., su origen serrano, su educación cristiana y el área geográfica en la cual se expandió su movimiento, es decir la selva central, hacen que este sistema sea especialmente complejo, mezcla de tres visiones diferentes, la andina, la cristiana occidental y la de las tribus amazónicas que se convirtieron en sus seguidores.

\section{CONTEXTO SOCIAL Y ECONOMICO DE LA REBELION: UNA COYUNTURA DE CRISIS}

Al estallar la rebelión de J.S.A., en 1742, en la selva central, hacía ya un siglo que el gobierno colonial había delegado la evangelización de la zona a la orden franciscana. Después de largas polémicas sobre el modo de atraer a los nativos a la religión cristiana, la conquista pacífica y sin armas sugerida por los frailes mendicantes tuvo que adaptarse a la realidad. Unos cuantos encuentros con los nativos demostraron que había rechazo y se llegó a la conclusión de que lo mejor era efectuar una evangelización protegida. En otras palabras, evangelización en la que la presencia de soldados se mostraba necesaria.

Así, con ayuda militar, durante todo el siglo XVII, los franciscanos hicieron esfuerzos ilimitados por mantener misiones estables en la selva central, siendo los resultados magros pues sus intentos acababan topándose siempre con la resistencia de los nativos a congregarse en pueblos de misiones.

Es recién a partir del siglo XVIII que los franciscanos comienzan a tener cierto éxito en la selva central. En los comienzos de ese siglo, el resurgimiento 
de las misiones estuvo estrechamente ligado a la figura del padre Franciscano de San José, fundador del Convento de Ocopa desde el cual se organizó a partir de entonces toda la actividad misional. Fue este personaje quien dirigió esta nueva etapa de evangelización en la zona.

La selva central había sido dividida en tres grandes conversiones o conjunto de misiones, partiendo de Tarma, Huánuco y Jauja. En 1709 se reinstauró la conversión de Tarma, que giraba alrededor del río Perené. Se fundaron misiones cerca al Cerro de la Sal controlado por la tribu amuesha, pero al cual acudían numerosas otras tribus en busca del preciado producto. Los franciscanos se percataron rápidamente de la importancia del lugar en tanto punto de encuentro interétnico.

En 1712, se reinstauró la conversión de Huánuco centrada a lo largo del río Huallaga y en 1713 la de Jauja que abarcaba la zona del Pangoa.

El área de la selva central estaba entonces habitada por dos tribus: los amueshas, llamados en los documentos de la época "amages", y los ashánincas denominados vulgarmente "campas". Como resalta el antropólogo F. Santos, (5) uno de los medios más eficaces por esos años de atraer a los nativos fue el de regalarles herramientas. El hierro maravilló a los indígenas que hasta entonces sólo trabajaban con utensilios de madera, hueso o piedra. Los franciscanos se percataron de este interés quejándose de que "...los más de estos indios sólo eran cristianos de nombre, y solamente se sujetaban por las golosinas de las herramientas que les daban los Padres"(6).

Pero la presencia de los franciscanos en la selva significó a la larga un factor de desintegración social y económica que acabó afectando a todos los nativos de la región y creando un ambiente de descontento que pronto se canalizó en la rebelión de J.S.A.

Muchos fueron los factores que hicieron viable un alzamiento de la magnitud del de 1742. Entre los más resaltantes seencuentra el delas periódicas epidemias, sobre todo de viruela y de cólera, que asolaron en todo el virreynato peruano y mermaron también las misiones franciscanas de la selva. Se han registrado diferentes epidemias en la selva central en los años 1673, 1691,1722/ 23, y 1736/37 (7). Los casos hablan por sí mismos. En 1725, en la misión de Sonomoro, la más populosa de la conversión de Jauja, se registraron 210 habitantes. El padre misionero se preocupó por anotar que "antes de la peste" vivian en ese lugar 800 nativos. Ese mismo año se anotó que en total la 
conversión de Tarma contaba con 1500 adultos bautizados. Antes de la peste, una vez más, eran 3500 los convertidos a la nueva fe (8). Ejemplos de este tipo se multiplican. Las epidemias fueron motivo de descontento y alentaron muchos movimientos de menor envergadura que el de J.S.A., pero importantes de tener en cuenta. Entre los amuesha, F. Santos piensa que, al parecer, esta tribu interpretó las epidemias como un castigo por dejar de lado a sus divinidades tradicionales (9).

Pocos años antes de sublevarse J.S.A., el gobierno colonial encábezado por el Virrey Castelfuerte (1724-1736) se mostró sin embargo indiferente al problema. Pienso que es a partir del gobierno de este Virrey que las misiones franciscanas de la selva comenzaron a sentir con mayor fuerza una presión del sistema colonial. Castelfuerte, empeñado en aumentar los ingresos de la hacienda real, efectuó un censo general destinado a evaluar las consecuencias demográficas de la epidemia de cólera que, surgida en 1719 en Buenos Aires, había logrado esparcirse por todo el virreynato. El Virrey tenía la sospecha de que esta epidemia había servido de pretexto para disminuir el número de tributarios y que un nuevo censo arrojaría una cantidad mayor (10).

Hasta ese momento, los informes demográficos de las misiones sel váticas no eran periódicos y se hallaban básicamente en manos de los franciscanos. A partir de 1725 se registran los primeros censos supervisados esta vez por los Corregidores de las provincias contiguas a las misiones (11). La presencia de los Corregidores es significativa. La gran decadencia demográfica en que se hallaba el virreynato volvía urgente la conquista de nuevos territorios y con ella la integración de sus habitantes al sistema colonial. También es sintomático que una de las primeras reacciones de los nativos al sublevarse fuera la de quemar o arrojar al río todos los padrones queexistían en las misiones. Mientras tanto el Virrey escribía en su memoria, al hablar de estas misiones, que con ellas había que "extender con el bautismo el vasallaje" y alentar "el aumento en la población de este reyno... siendo éste el mejor medio de reparar la gran decadencia en que se halla..." (12).

Desgraciadamente no se han hallado aún documentos que se refieran directamente a las actividades económicas de la zona y a la integración tributaria de los nativos al sistema colonial. Existen, sin embargo, algunas menciones aisladas que permiten hacerse una idea muy global del problema.

Ya en 1718, se registra la presencia de un "diezmero" en la misión de Quimiri de la conversión de Tarma. Fray Francisco de San José, escribiendo 
a otro religioso y contándole la introducción de un importante hato de ganado en aquella misión, se refiere que "al diezmero se le avisa que vaya por su dinero, porque aquel ganado lo han dado y es de los indios y no de los frailes..." (13). El diezmo era un importante tributo eclesiástico que se pagaba en tiempos de la colonia en base a lá producción agropecuaria. En 1742, año de la rebelión de J.S.A., el diezmo continuaba cobrándose en Quimiri y en "otras misiones" tal como lo señaló el propio diezmero (14). De estos dos documentos, se desprende que, no sólo los nativos estaban ya obligados a cumplir con el pago del diezmo, sino que además lo hacían con dinero, y no con productos. Para ello era necesario haber sido incorporado de alguna manera al circuito económico comercial, el único capaz de proporcionarles la moneda.

Un factor claro de descontento de parte de lo nativos lo constituían los repartos forzados de mercancías distribuidos por los Corregidores a precios mucho mas elevados que los reales. Descontento que compartieron con los propios franciscanos que se quejaban continuamente al Virrey de este asunto, solicitándole que las misiones no dependieran de estas autoridades sino de funcionarios especiales sugeridos por los frailes y ratificados por el Gobierno. El Padre Nuñez; Comisario de misiones en la época de la rebelión de J.S.A., anotaba en un informe sobre el estado de estos pueblos en la selva "que pudieran ser más si no fuera por los repartos que hacen los Corregidores, y pide que no reparta, ni tenga autoridad alguna en las conversiones." (15). Alfonso Santa, Corregidor de Tarma al momento de alzarse J.S.A., se había ganado fama de repartir mercancía a la fuerza y de tener problemas con los indios por lo que estos le quedaban debiendo. Se rumoreaba incluso que Santa había sido tomado preso en 1745 por orden del propio Virrey y que constaba "... haber repartido 100.000 pesos de géneros, en precios tan subidos que llegaban a la cantidad de 800.000 pesos." (16) La actitud de los Corregidores alarmaba al propio Virrey Villagarcía, que en 1744 en una carta al Rey contaba que les había advertido "...que con sus operaciones y excesos no diesen lugar a que las quejas de los indios les hiciesen atribuir su conmoción" (17).

La obligación de pagar diezmos sumada al endeudamiento por los repartos de mercancias, vuelve probable el que los nativos se ofrecieran como mano de obra barata a los lugares más accesibles. Estos eran las ricas haciendas de cacao, azúcar, tabaco y otros productos que ya se cultivaban en la región y los obrajes, pequeños centros textiles, que operaban en sus inmediaciones.

Existen datos que demuestran que los nativos eran trasladados a obrajes para poder pagar las deudas contraídas a la fuerza. Es nuevamente significativo 
que J.S.A. se encargase de destruir el obraje de Colpas en Tarma que había sido alquilado en 1724 por el Corregidor de Tarma, Don Juan Arozamena, "...que en el tiene sobradísima gente por la que mete de por fuerza para que con su trabajo desquiten lo que deven (18).

Pero la presión no venía exclusivamente desde fuera. También los franciscanos alentaron la incorporación económica de los nativos sobre todo a través del comercio.' A través de las misiones se forzó al nativo a abandonar su nomadismo y a trabajar nuevos cultivos y oficios que resultaban más rentables para la orden.

Si a esta nueva organización económica a la que se sometió a los nativos se le suma el impacto sicológico que significó imponerles una nueva religión, un nuevo sistema de valores que en nada podía serles familiar, se puede llegar a entender la acogida de un movimiento como el de J.S.A. La coyuntura de crisis se cumplía a cabalidad. Los nativos eran en el siglo XVIII seres cuyo sistema de vida se había visto radicalmente afectado por la penetración franciscana.

\section{LA REBELION, UN MOVIMIENTO ANTICOLONIAL}

Es en el contexto que acabo de describir que aparece en la misión de Quisopango o Simaqui (la más inaccesible de todas), en 1742 un mestizo de unos 30 años de edad, de quien no se sabe si ha nacido en Cusco, Huamanga - Cajamarca, que se proclama descendiente directo de Atahualpa y por ello legítimo gobernante del Perú. El movimiento fue planeado con anterioridad. 'De los pocos datos biográficos que se tienen de este líder, se sabe que recorrió toda la sierra, desde Cusco a Cajanarca, de 1729 a 1730 declarando que "...quería restaurar su reino del poder de los españoles..." (19). Esta versión es corroborada tiempo después cuando el Corregidor de Jauja, Marqués de Casatorres, en 1752, afirmó estar al tanto de que J.S.A. estuvo en Jauja en 1731 y que "... vino desde la ciudad del Cusco alternando los pueblos y conmoviéndolos, de tal manera, que ya empezaba el efecto del movimiento; $Y$ dio causa para que aquí fuese aprehendido y remitido preso a la disposición del excelentísimo Señor Marqués de Castellfuerte, siendo Virrey de estos reinos; y tuvo modo de hacer fuga de la Piedra, a donde dice fue desterrado y al cabo de tiempo de internó a la montaña..." (20).

J.S.A., llegó a territorio campa acompañado de un Piro llamado Bisabequi a quien se describe como un anciano de unos 130 años, posiblemente 
un shamán que lo habría introducido al mundo amazónico. Desde la misión de Quisopango expandió su mensaje que llegó a abarcar las regiones de los rios Chanchamayo, Perené, Ene, Pangos y Alto Ucayali. Todas, regiones con misiones franciscanas. La zona ocupada pertenecía en ese entonces a la jurisdicción de Tarma y Jauja y dependía de la Audiencia y del Arzobispado de Lima. Desde esa área, la de la selva central, era fácil presionar a las ciudades de Pasco, Tarma y Jauja, todas centros urbanos de importancia en la época. La rebelión fue larga, pues duró unos diez años, aunque sus efectos se hicieron sentir casi por un siglo.

J.S.A., no llamó a participar en el movimiento exclusivamente a los nativos, sino que la rebelión contó con una participación masiva de serranos y en menor escala, negros. Es importante la participación serrana en este alzamiento para llegar a entender el discurso ideológico del líder J.S.A., que incorporó a los andinos en su programa al predicar que los liberaría del yugo español y llamarlos sus vasallos.

La presencia serrana era frecuente en muchas de las misiones de la selva. La selva fue siempre vista por los andinos, desde tiempos prehispánicos, como un lugar de refugio, una región en donde esconderse sin dejar huella. En tiempos coloniales los serranos huían sobre todo de la mita, del trabajo en los obrajes, de los numerosos tributos y de los "repartos" de mercancias. El elevado número de seguidores serranos en la rebelión de I.S.A., se explica tomando en cuenta a los que estaban establecidos desde hacía tiempo en las misiones selváticas en calidad de "forasteros" $\mathrm{y}$, además, a los que, desde la sierra, se sintieron atraídos por el discurso de este líder. El éxito del rebelde entre la población andina alarmó de' sobremanera a los funcionarios coloniales que temieron que la rebelión se expandiese por todo el Perú. El gobierno colonial organizó un total de seis expediciones militares destinadas a sofocar el movimiento... Todas fracasaron.

Amedida queavanzaba la rebelión y que los franciscanos iban perdiendo sus misiones, la actitud del gobierno fue cambiando. Con la llegada del nuevo Virrey Manso de Velasco, Conde de Superunda en 1745, se arribó a la conclusión de que estas expediciones eran excesivamente costosas y daban pocos resultados y que lo mejor era cortarles toda comunicación con la sierra.

En 1752, el Corregidor de Jauja, Marqués de Casatorres, declaraba que consideraba la provincia a su cargo "... ligada con secretas inteligencias con el revelde, enemigo declarado..." (21). El hecho en concreto es que J.S.A., 
mantenía espías en la sierra y a tra vés deellos se hallaba siempre bien informado de lo que ocurría fuera.

Pero, ¿en qué consistió el éxito de su discurso?, ¿Cuál fue su programa político?, ¿cuáles fueron sus reivindicaciones económicas y sociales? En cuanto a sus demandas políticas J.S.A., encabezó un movimiento claramente anticolonial e indigenista pero cuyos lineamientos no fueron nada claros. En junio de 1742, en la primera entrevista lograda por un franciscano, el Padre Santiago Vasque de Caicedo, J.S.A. declaró "... que su animo era salir a coronarse a Lima, que no quería pasar a España ni a reino que no fuese suyo..." (22), que todos aquellos que no hubiesen nacido en América habrían de salir de ella (expulsaba por lo tanto a peninsulares y a negros), "... que el Virrey podía tener a bien dejarle tomar posesión de sus reinos; que si salía a estorbarle con cuatro españoles el tenía sus hijos los indios y mestizos y a los negros..." (23). Un informe posterior de dos franciscanos basado exclusivamente en la versión de dos negros que huyeron del líder, aclara un poco más el panorama. J.S.A., pretendía recobrar la corona que le quitó Pizarro a su padre, es hijo del inca y por lo tanto dice tener derecho a gobernar. El rebelde sugiere que el propio Virrey sea quien le restituya esta corona y que si no, la tomaría por la fuerza. Hay que resaltar que los primeros años de la rebelión muestran a un J.S.A. pacífico, que trata de evitar el contacto armado. En 1745 declara que "... no quería hacer mal a nadie sino que le diesen lo que era suyo..." (24).

En cuanto a la forma de gobierno, J.S.A., nunca fue claro al respecto. Había de ser obviamente un gobierno compuesto por indígenas, criollos y mestizos en tanto la única condición para pertenecer a él era la de haber nacido en estas tierras. Crítica a los gobernadores y corregidores que espantan y explotan a los indios, "... y que ya ahora no hay más Governador, ni más Rey que él..." (25). En sus escasos discursos no aclara nada más, a menos que las personas que escribieron sobre ello olvidaran tan importante aspecto. Lo dudo, aunque hay que precisar que ninguna de las fuentes referentes a J.S.A., es directa; es decir que J.S.A., nunca dejó un manifiesto personal y que todo lo que se sabe de él es siempre a través de terceros.

Un documento de 1743, que se atribuye de manera incierta a Don Benito Troncoso, Gobernador de la Provincia de Jauja, que dirigió varias de las entradas militares destinadas a sofocar la rebelión, registra unos datos que a decir verdad enturbian aun más el panorama político. "Tocante al Virrey dice ser muy preciso en estos reinos, por ser muy dilatados y que el actual por el Rey de España este tiene la culpa que es la envidia, y que si reconociese que 
es capaz se mantendría hasta confirmación suya y sino lo despachara como a tal persona. Hablando de los oidores dice que unos vienen por el Rey, y otros por sus pretensiones..." (26). De acuerdo a esta cita J.S.A., demostraba cierto respeto por la personal real y más bien cuestionaba sin ánimo la necesidad de suprimir, las autoridades coloniales. En todo momento durante la rebelión, queda claro que J.S.A. esperaba convocar a' los curacas serranos para lograr su meta. Esta convocatoria, sin embargó, nunca se concretó, registrándose tan sólo casos aislados de adhesión entre las máximas au toridades indígenas. Es probable que esta ausencia de éxito entre los curacas influyese en la aparente inexistencia de un programa político global y coherente en esta rebelión.

Los argumentos de orden económico son igualmente vagos. Promete a sus seguidores la desaparición de los obrajes, de las panaderías donde muchos de los indios cumplian sus penas y de las "esclavitudes en general". "No ha de permitir en su reino esclạvos, ni las demás tiranías de los españoles..." (27).

\section{ASPECTOS IDEOLOGICOS DE LA REBELION}

Si las referencias políticas y económicas de J.S.A., son ciertamente limitadas y hasta contradictorias, su mensaje abunda en cambio en connotaciones místicas y religiosas que dan cuenta del origen mestizo del líder al mezclarse tradiciones andinas, con un discurso cristiano al pasar el tiempo cada vez menos ortodoxo, además de referencias a la cosmovisión de amazónica. Todas estas referencias adquieren, por cierto, rasgos eminentemente milenaristas en tanto se refieren a un gran cambio próximo a realizarse; todas aluden a algún tipo de salvación.

El primero en analizar la rebelión de J.S.A., como un movimiento milenarista fue M. Curátola en un breve artículo aparecido en 1978. (28). Un trabajo más amplio y exhaustivo se debe recientemente al antropólogo $\mathrm{A}$. Zarzar (29), quien rescató los elementos milenaristas del discurso de J.S.A., basándose en sus tres vertientes, la andina, la occidental y la amazónica, haciendo un interesante estudio de la evolución de su pensamiento de 1742 a 1752 .

Como sucede con todo movimiento milenarista, el líder (en este caso identificado con el Mesía, s pues J.S.A., indica ser enviado por Dios para efectuar una misión en la tierra) poseía un magnetísmo personal que lo hacía diferente al común de los hombres. Intelectualmente se presentaba superior al resto 
de los mestizos. Se lo consideraba un sabio pues al parecer no sólo hablaba quechua sino también sabía hablar y escribir en latín y en castellano, idiomas que habria aprendido estudiando en un colegio de jesuitas en el Cusco. Al proclamarse descendiente directo del Inca Atahualpa, afirmaba pertenecer a un linaje real y no gentil. M. Curátola anota que "...en los siglos XVII y XVIII la figura mesiánica del Inca fue uno de los principales móviles y una constante de las numerosas rebeliones indígenas que marcaron la historia colonial," (30). Queda claro entonces que el fenómeno de J.S.A. no era un caso aislado en la época. Por último muchas de las características y actividades del líder lo equiparan a divinidades, mitos e incluso santos populares por esos años.

Uno de los mitos recreados por J.S.A., fue precisamente el mito de Incarri - Incarrey, dios creador de todas las cosas según la mitología andina, que fue decapitado por los españoles en la conquista. Según afirma la leyenda, Incarri al morir hizo desaparecer todas sus riquezas y ha de volver algún día cuando su cabeza vuelva a unirse al cuerpo para reinvertir el orden implantado por los españoles. J.S.A se atribuyó varias de las características de dicho mito. En 1742 afirmó que su objetivo era "...cobrar la corona que le quitó Pizarro y los demás españoles a su padre (que así llama al Inca), enviando su cabeza a España..." (31). Por otro lado, decía ser capaz de dominar los elementos naturales. Sostenía poder retener al sol, producir terremotos y ser capaz de convertir las piedras en oro. Todas manifestaciones propias de Incarri. Al igual que esta divinidad andina, J.S.A. decía poseer mucho oro y plata y advertía a sus seguidores que no se dejasen impresionar por su aspecto de pobreza. Todas sus riquezas se hallaban escondidas esperando la ocasión para utilizarlas del mismo modo que Incarri.

Finalmente, J.S.A. mencionaba también que a los españoles se les había acabado el tiempo y que habían llegado el suyo. La mayoría de los andinos había interpretado la conquista como un Pachacuti es decir "un cataclismo cósmico y periódico que marca el fin y el inicio de cada edad de la humanidad" (32). En muchos de los movimientos milenaristas andinos se registra también esa tendencia a superar el Pachacuti para alcanzar otro tiempo. Al referirse a tiempos pasados y venideros, J.S.A. aludía claramente a esta visión.

Este tipo de menciones místicas andinas en el discurso de J.S.A. explica el poder de convocatoria que tuvo el líder entre los andinos. A hora bien, ¿hasta qué punto fue posible que las tribus amazónicas, que fueron el grueso de los seguidores de J.S.A., aceptaran un discurso que aludía tan claramente a mitos panandinos y en particular el retorno del Inca? Para entender este punto hay 
que analizar en primer lugar, qué significaba el retorno del Inca en este tipo de movimientos, y en segundo lugar, cómo podía adaptarse esta figura a la cosmovisión amazónica.

En lo que se refiere a la figura del Inca, F. Pease (33) encuentra que lós movimientos tempranos milenaristas en los, Andes solieron identificar esta figura más que con el gobernante del Cusco, como una categoría que existía antes del Tahuantinsuyo referida a un principio de orden, felicidad y abundancia. Inca, entendido como todo lo anterior a lo español, se convirtió para los andinos en un principio fundamental perdido a raíz de la conquista. Regresar al tiempo del Inca, como afirma M. Curátola (34), no se entendía necesariamente como retornar al período histórico del Tahuantinsuyo, sino como un tiempo ideal. A través de los años, Inca como principio fundamental e Inca, gobernante del Cusco, tendieron nuevamente a confundirse dando origen a mitos como Incarri.

En cuanto a la aceptación de este discurso entre las tribus amazónicas, es curioso constatar que "lo Inca" no era tan extraño entre ellas. Después de largos años de trabajo de campo, F. Santos ha logrado demostrar que son precisamente los amueshas, es decir la tribu que más contacto tuvo con J.S.Al., los que tienen una cosmología mas semejante a los Incas. Su Dios principal, Yonpor Ror, representa también el sol. Ahora bien, Santos anota que en general el Inca aparece en la mitología de todas las tribus involucradas en la rebelión de J.S.A., con características divinas o semi-divinas (35). Así, entre los campas, amueshas, piros, machiguengas, conobis, shipibos y cashibos, el Inca era una figura conocida.

Un antropólogo como E. Fernández corrobora lo dicho por Santos entre los ashánincas. E. Fernández recopiló mitos en los ríos Tambo y Ene (territorio asháninca) de 1981 a 1982. (36) Todos son mitos que aluden a la muerte del Inca y al origen de los hombres blancos. Fernández pudo constatar que estos mitos son todos semejantes a los del Incarri andino, mitos que no sólo explican desde su propio punto de vista la derrota del Inca (por haber cometido incesto o usar del trabajo esclavo de parientes), sino también la esperanza del retorno de él y del orden alterado por la llegada de los españoles. E. Fernández concluye que existe una relación ideológica muy estrecha entre la población andina y los ashánincas.

Pienso que la presencia de andinos en la selva desde tiempos prehispánicos debió influir en este sincretismo ideológico entre andinos y selváticos. Sería interesante verificar hasta qué punto J.S.A. contribuyó a él. 
Otra de las vertientes en el discurso de J.S.A. fue la cristiana occidental. Para sorpresa de muchos franciscanos, J.S.A. se presentó en un comienzo como un buen cristiano que cumplía con los preceptos de la religión católica y con ciertos rasgos de asceta como aquél de huir del trato de las mujeres y alimentarse frugalmente. Sostenía que "...no quiere introducir ley nueva sino la que predican los misioneros..." (37). A pesar de eso, se identificó desde el principio con el mesias declarando haber sido enviado por Dios. Al comienzo, discrepa únicamente en dos puntos con los franciscanos. El primero, pretendiendo que los jesuitas y no los mendicantes se encargasen de ahí en adelante de la evangelización de la selva central. El segundo, al buscar establecer un clero indígena como declaraba haber visto en Angola, reino al que decía haber viajado en compañía de los jesuitas.

En 1743, un cronista cusqueño, Diego Esquivel y Navia, no duda aún en compararlo con San Francisco al escribir que "...habiéndole echado varias fieras, como leones, tigres, etc, una nación de caribes, que le resistían, les mostró el crucifijo que llevaba al pecho y se le humillaron las fieras" (38).

En 1747,J.S.A.utiliza cada vez más claramente expresiones apocalípticas, anunciando el fin de los tiempos. En 1750 los documentos lo presentan ya como un hereje que se proclama hijo de Dios y dice ser la reencarnación del Espíritu Santo. Ese año, una relación escrita por el Padre Fray Francisco de San Antonio lleva un título sugerente: "De la doctrina, errores y herejías que enseña el fingido rey Juan Santos A tahualpa, Apuinga, Huayna Capac, en las misiones del Cerro de la Sal, indio rebelde, enemigo declarado contra la ley de Dios y traidor al rey Nuestro Señor que Dios guarde." (39). Herejía y traición se habían confabulado en un mismo personaje. Juan Santos Atahualpa se había convertido en un falso mesías que predicaba el fin de.este mundo y el surgimiento de uno nuevo en una amalgama de creencias que resultaron incoherentes en la época.

\section{NOTAS}

(1). M. Curátola. Discurso abierto sobre los cultos de crisis. En: Antropológica, PUCP año V, No 5, 1987.

(2). N. Cohn. En pos del milenio, Alianza Editorial , 1989.

(3). M. Curátola. Ibídem.

(4). N. Cohn. En pos del milenio, Alianza Editorial, 1989.

(5). F. Santos. Templos y herrerpias: Utopía y re-creación en la amazonía peruana (siglo XVII - XIX). En: Boletín del Instituto Francés de Estudios Andinos, No 2, 1988. 
(6). I. Amich. Historia de las misiones franciscanas del Convento de Ocopa, Editorial Milla Batres, 1975.

(7). G. Weiss. Campa cosmology. In Antropological papers of the American Museum of Natural History, Vol. 52, Part 5, New York, 1975.

(8). F. Radríguez Tena. Misiones de la Santa Provincia de los Doce Apóstoles de Lima del Orden de N.P.S. Francisco, Lima, 21780? Archivo de Ocopa 84.

(9). F. Santos. Vientos de un pueblo, síntesis histórica de la etria amuesha, siglo XVII - XVIII, Lima PUC. Tesis de Licenciatura. Inédita. 1980.

(10). S. O'Phelan. Un siglo de rebeliones anticoloniales. Perú y Bolivia 1700-1783. Centro de estudios rurales andinos Bartolomé de las Casas, Cusco, 1988.

(11). F. Rodríguez Tena, Ibídem.

(12). Fuentes, M.A. Memorias de los Virreyes, Lima, 1859.

(13). Carta de Fr. Francisco de San José, Comisario de misiones al P. Comisario General, Lima, sept. 1718. Archivo General de Indias. Lima 537.

(14). F. Loayza. Juan Santos el invencible. Impresa Miranda, Lima, 1942.

(15). Indice de Ocopa, Folio 331, sin año.

(16). D. Esquivel y Navia. Noticias cronológicas de la ciudad del Cusco, 2 tomos, Fundación Wiese, Lima 1980.

(17). F. Loayza. Juan Santos el invencible, Lima 1942.

(18). Autos promovidos por Don Francisco Dávila Torres... contra Don Juan Arozamena. Archivo General de la Nación. Derecho indígena. C812. Leg. 39.

(19). F. Loayza. Juan Santos el invencible, Lima, 1942.

(20). Causa seguida contra Julián Auqui, Blas Ibarra y Casimiro Lamberto... Archivo General de la Nación. Real Audiencia. Causas criminales. C159. Leg. 15.

(21). Causa seguida contra Julian Auqui......AGN. C159. Leg. 15

(22). J. Amich. Historia de las misiones franciscanas del Convento de Ocopa. Ed. Milla Batres, 1975.

(23). F. Loayza. Juan Santos el invencible. Lima, 1942.

(24). J. Amich. Ibídem.

(25). F. Loayza. Juan Santos el invencible. Lima 1942.

(26). F. Loayza. Ibídem.

(27). J. Amich. Ibidem.

(28). M. Curátola. Mito y milenarismo en los Andes. En: Allpanchis, num. 10, Cusco, 1978.

(29). A. Zarzar. Apo Capac Huayna, Jesús Sacramentado. Eds. CAAAP. Lima, 1989.

(30). M. Curátola. Discurso abierto sobre los cultos de crisis. En: Antropológica, PUCP., año V, num. 5, 1987.

(31). F. Loayza. Juan Santos el invencible, Lima, 1942.

(32). M. Curátola. Mito y milenarismo en los Andes. En: Allpanchis, num 10., Cusco, 1978.

(33). F, Pease. Los últimos incas del Cusco. Lima, 1981.

(34). M. Curátola, Ibidem.

(35). F. Santos. Vientos de un pueblo... Tesís de licenciatura, 1980.

(36). E, Fernández, Los Ashanincas y los Incas. Historia y mitos. En: Rev. Antropológica, año V, num. 5, 1987.

(37). F. Loayza. Juan Santos el invencible. Lima, 1942.

(38). D. Esquivel y Navia. Noticias cronológicas de la ciudad del Cusco. Fundación Wiese, Lima, 1980.

(39). M. Castro Arenas. La rebelión de Juan Santos, Ed. Milla Batres, Lima 1973. 